\title{
The Associations between Periodontitis and Respiratory Disease
}

\author{
Somaye Ansari Moghadam, ${ }^{1}$ Masoomeh Shirzaiy, ${ }^{2}$ Sirus Risbaf ${ }^{3}$ \\ ${ }^{1}$ Department of Periodontology, School of Dentistry, Zahedan University of Medical Sciences, Zahedan, \\ Iran, ${ }^{2}$ Oral and Dental Disease Research Center, Zahedan University of Medical Science, Zahedan, Iran, \\ ${ }^{3}$ Department of Oral Surgery, School of Dentistry, Zahedan University of Medical Sciences, Zahedan, Iran.
}

\section{ABSTRACT}

\begin{tabular}{|l} 
Researches have shown positive correlation between periodontitis and respiratory diseases such as chronic obstructive \\
pulmonary disease. We reviewed the literature to assess the relationship between periodontitis and respiratory diseases. \\
This study involved a review of relevant English literature published regarding periodontitis and respiratory diseases \\
during the period of 1994-2015. The analysis of literature related to the topic showed there is association between \\
periodontitis and respiratory diseases such as chronic obstructive pulmonary disease and pneumonia. It was found that \\
periodontitis is associated with respiratory diseases due to poor oral hygiene and low immunity state. \\
Keywords: Inflammation; oral hygiene; periodontitis; respiratory illness. .
\end{tabular} \mid

\section{INTRODUCTION}

The tissues supporting the teeth are collectively called the periodontium of the teeth. The inflammatory process involving the periodontium is called periodontitis that causes progressive loss of alveolar bone surrounding the tooth structure with loosening and subsequent loss of teeth. It is usually caused by microorganisms that get adherent to tooth surface and grow in its vicinity with aggressive immune response against these and thus causing swelling, redness, congestion, and pain in tissues surrounding the teeth. ${ }^{1}$

Many researches have defined a probable role for periodontal disease as a risk factor for systemic diseases, ${ }^{2}$ consists of diabetes, ${ }^{3}$ osteoporosis, ${ }^{4}$ cardiovascular diseases, ${ }^{5}$ adverse pregnancy outcome, ${ }^{6}$ rheumatoid arthritis, ${ }^{7}$ and respiratory disease such as chronic obstructive pulmonary disease (COPD). ${ }^{8,9}$

The chronic obstructive pulmonary disease is an inflammatory condition with progressive deterioration of pulmonary function and increasing airway obstruction ${ }^{10,11}$ consists of emphysema and chronic bronchitis. ${ }^{10}$ Oral microorganisms can be easily carried into the lungs and cause infection. ${ }^{12}$ Also, COPD and periodontitis have common risk factors, such as obesity, older age, smoking, low socioeconomic status, etc. ${ }^{2}$

Many researches ${ }^{13-33}$ have defined the positive association between periodontitis and COPD. However, different researches have assessed different populations and applied various assessment methods. ${ }^{34}$
Globally, hygiene control is improving; but, it is inadequate and the COPD burden will rise in near future due to population rise as suspected. ${ }^{1}$ We will discuss if the periodontitis is associated with any respiratory illness or not and what are the causes and subsequent outcomes of the pathological process along with diagnostic, treatable, and preventive measures available to control the disease.

\section{LITERATURE ANALYSIS}

The research was undertaken by reviewing the English published articles on periodontitis and respiratory illnesses since 1994 to 2015. The following search terms were used: (1) periodontal disease, periodontitis, periodontal, periodontium, and (2) respiratory illnesses/ infections, asthma, COPD, and pneumonia. The sites that were searched include PubMed, Journal of Clinical Periodontology, Journal of Medicine and Life, Public Library of Science (PLoS), Springer, Expert Review of Respiratory Medicine, International Journal of Dental Research, Annals of Periodontology and BMC Medical Journal. The sorted results were first evaluated on the basis of their respective titles and abstracts and afterwards complete text of the selected published study was obtained on the basis of selection criteria as described below. Proper literature analysis was done with analyzing scales grading these diseases as per WHO criteria. Abstract-only studies, letters, animal model 
studies, and case reports were excluded from the search.

\section{SELECTION OF STUDY}

Studies conducted on periodontitis and respiratory illnesses were selected and reviewed. Only studies based on human patho-physiology rather than animal model studies were selected. Study types including cross-sectional, case control, or cohort design was included. The studies that mentioned diagnostic criteria for periodontitis and respiratory infections along with those showing the association between these two were selected to collect data from.

\section{DATA COLLECTION}

Patient data with significant periodontal and respiratory illness was extracted and evaluated from the selected studies to achieve the understanding for the presence of any relationship if present between these two diseases of periodontitis and respiratory infections. Data extracted was recorded as per first author's last name, the year of publication, and the country in which it was carried out along with number of participants and those with periodontitis and respiratory infections. Periodontitis was defined and graded as per WHO criteria ${ }^{35}$ on the basis of degree of gingival inflammation, loss of connective tissue and alveolar bone, and increasing probing depths up to pockets. Gingival inflammation was evaluated on the basis of gingival index, plaque index, and oral hygiene index ${ }^{35}$ all of which are key points to be noted while checking for the degree of tissue inflammation. Similarly, data related to probing depths in pockets was sorted and critically analyzed to evaluate the association between tissue inflammations at different sites in teeth in relation to the size of pocket while examining probing depth.

Data showed that there is association between periodontitis and respiratory diseases such as COPD, pneumonia, asthma, and other upper respiratory illnesses, which is mostly associated with poor oral hygiene and low immunity status. In present study, a total of 51 articles were searched for assessment of relation between periodontitis and respiratory disease specially COPD.

These articles were evaluated by the reviewers. The results were as follows: 1) A weak association between periodontal disease and COPD was defined in one study; 2) some studies noted that the link between periodontal disease and respiratory disease remains somewhat controversial; 3) one study reported that associating periodontal disease and COPD are preliminary and large-scale longitudinal and epidemiologic and RCTs are needed; 4) some studies reported that their findings do not support interaction between periodontal diseases and COPD; 5) many studies demonstrated that periodontitis were associated with respiratory disease such as COPD.

$\begin{aligned} & \text { Table 1. Total number of articles searched and } \\
& \text { included in the review. }\end{aligned}$
\begin{tabular}{|llll} 
Total & Numbers & Numbers & Numbers included \\
articles & relevant & excluded & for analysis \\
51 & 34 & 10 & 26 \\
\hline
\end{tabular}

Bansal et al., ${ }^{36}$ Cullinan and Seymoor, ${ }^{37}$ and Moghadam et al. ${ }^{38}$ have concluded that periodontitis is associated with systemic diseases, e.g., respiratory disease, chronic kidney disease, rheumatoid arthritis, atherosclerotic cardiovascular disease, aplastic anemia and cancers as well as minor disorders including cognitive impairment, obesity, and metabolic syndrome. In this paper, our focus will stay on respiratory diseases occurring secondarily to periodontitis. ${ }^{36-38}$

\section{PERIODONTITIS AND RESPIRATORY ILLNESSES}

Periodontitis is an inflammatory condition of tissues surrounding teeth. It may result in loss of surrounding alveolar bone and eventually the tooth. Many criteria exists globally for diagnosis of periodontitis but commonly agreed upon is WHO recommendation that includes gingival inflammation, loss of connective tissue and alveolar bone, increases in probing depths, and formation of periodontal pockets. ${ }^{35}$ On this basis, a clinician is able to suspect and diagnose the process of periodontitis. If there is uncertainty then it should be focused that the patient might have any other underlying disease conditions which should be evaluated for suitable treatment. The severity of this disease process is measured by grading it into 3 grades of mild, moderate and severe on the basis of classification through clinical attachment by measuring with a periodontal probe from cementoenamel junction to the base of periodontal pocket. ${ }^{39} \mathrm{As}$ reported periodontitis is a major cause of systemic disturbances including respiratory diseases, mainly chronic obstructive pulmonary disease and pneumonia. ${ }^{36,40}$ Aspiration of unhygienic oral secretions ${ }^{36,41}$ possibly induce an inflammatory response in airway mucosa causing respiratory illnesses. ${ }^{36,42}$

Data showed that there is association between periodontitis and respiratory diseases such as COPD, pneumonia, asthma, and other upper respiratory illnesses which is mostly associated with poor oral hygiene and low immunity status. As per the available data in various research papers, $60 \%$ of people with periodontitis face some form of respiratory illness at some point during the diseases process varying in severity. 
Table 2. Association between periodontitis and respiratory diseases

\begin{tabular}{|c|c|c|}
\hline $\begin{array}{l}\text { Prevalence of } \\
\text { periodontitis } \\
\text { according to } \\
\text { WHO }\end{array}$ & $\begin{array}{l}\text { People with } \\
\text { periodontitis } \\
\text { due to poor } \\
\text { oral hygiene }\end{array}$ & $\begin{array}{l}\text { People with } \\
\text { respiratory } \\
\text { disease due to } \\
\text { periodontitis }\end{array}$ \\
\hline $\begin{array}{l}15-20 \% \text { of world's } \\
\text { population }\end{array}$ & $90 \%$ & $60 \%$ \\
\hline
\end{tabular}

World Health Organization (Fact sheet $N^{\circ} 318$, April 2012)

\section{PATHOGENESIS OF PERIODONTITIS AND} RESPIRATORY INFECTIONS

Periodontitis, as discussed, is an inflammatory condition of gums. Contributing factors include poor oral hygiene, smoking, drug abuse, chronic plaque buildup causing dental caries, altered immune mechanism, old age, diabetes, etc. Periodontitis is mainly a neutrophil mediated inflammatory process. Therefore, excess of neutrophil reaction in periodontal tissues activate inflammatory focus in periodontium due to excessive neutrophilic enzymes leading to swelling, congestion, bleeding and eventually loosening of periodontium from dentures causing the teeth loss. All this occurs due to multiple effects including bacterial buildup, accumulation of food particles, poor hygienic control, genetic factors, and sometimes immunosuppressive states too. Therefore, intrinsic, environmental and genetic factors play a complex role in the process of periododntitis. ${ }^{43}$

Similarly, respiratory pathology of COPD is also a neutrophil induced response and has risk factors including pulmonary pathogen buildup in airway, poor oral hygiene, aspiration of irritant material into the airway, smoking and inadequate cough reflex. Lower airways are usually sterile ${ }^{36,44}$ despite secretion buildup from upper airway which is highly contaminated from oral and nasal surfaces. The sterility of lower airway passage is maintained through intact cough reflex, and outward beating of mucociliary layer that propels inhaled bacteria and irritant particles outward to the oropharynx and also due to intact immune and non-immune defense responses including surfactant layer containing fibronectin, complement proteins, immunoglobulins, and phagocytic cells to remove particulate debris. There are three main pathways for spread of infection to lungs, including hematogenous, airway contamination, and spread from other contagious sites ${ }^{36,45}$ nearby, such as oral cavity. Species of oral flora implied in lung infection includes Actinomyces israelii, Eikenella corrodens, Porphyromonas gingivalis, Actinobacillus actinomycetemcomitans, Prevotella intermedia, and Streptococcus constellatus. ${ }^{36,45}$ These organisms may get adherent to mucosa, can be aspirated along with oral secretions, may get resistant to salivary degradation enzymes, and may alter the cytokine composition that may affect respiratory epithelium to promote infection by these pathogens. ${ }^{36}$

\section{COMMON DISEASES IN LUNG POSSIBLY DUE TO PERIODONTITIS AS SUPPORTED BY COPD}

Periodontitis may worsen systemic diseases, including pulmonary diseases. Study form India mentioned that patients with pulmonary disease usually have poor oral hygiene and smoking is also a major risk factor for both periodontitis and pulmonary disease. ${ }^{30}$ The COPD is a chronic inflammatory condition of airway passage characterized by airflow obstruction with progressive inflammation of pulmonary mucosa. Airflow obstruction in this process seems to be due to those harmful particles or gases that are inhaled during breathing. Major risk factors for COPD are chronic smoking, variant a1-, a2-macroglobulin, and defective a1-antitrypsin gene, vitamin $\mathrm{D}$ binding protein, antichymotrypsin, and blood group antigen genes. ${ }^{36,46}$

Worldwide prevalence of COPD is $9-10 \%$ in age above 40 years with more population affected in developed countries due to increased smoking habits. ${ }^{46}$ Moreover, COPD is shown to be aggravated by any other fungal, viral, or bacterial infection suppressing the primary condition. The link between periodontitis and COPD was shown in 1998 in NHANES data suggesting that periodontitis might be a co-factor for pulmonary involvement, but it was found that periodontal condition is not associated with the number of exacerbations of obstructive pulmonary diseases. ${ }^{47}$

\section{PNEUMONIA}

Oral cavity is important reservoir of pulmonary pathogens, Staphylococcus aureus, Pseudomonas aeruginosa, and other enteric species. ${ }^{48}$ Avoiding or limiting aspiration, minimizing colonization, careful use of antibiotics, and invasive devices are some preventive measures. Linden et al. in 2013 showed that poor oral hygiene and periodontitis, especially among smokers, is an important cause of increase in nosocomial pneumonia. ${ }^{46}$ It was also shown that efforts to reduce oral microbial load resulted in reduced cases of pneumonia. Saliva and plaques of patients containing pulmonary pathogens were proven to be a risk factor for aspiration pneumonia. Frequent professional oral health care has been shown to reduce and control the incidence and severity of associated respiratory diseases. ${ }^{49}$

\section{PERIODONTAL DISEASE AND ASTHMA}

Asthma is characterized by recurrent episodes of breathlessness, cough, wheezing, chest tightness, and 
sometimes pus like discharge during recovery phase. The pus like discharge during recovery is suggested to be due to high level of eosinophils in white blood cell component as an allergic response. The association between periodontal disease and asthma is suggested to involve immune activation due to inflammatory nature of both disorders. Serum IgA of saliva secretions tend to be first line defense mechanism for the mucosa and play a major role in preventing periodontitis. Serum IgA is reduced in saliva secretions of asthmatic patients and also the destruction of periodontum is higher in these patients as assessed by Periodontal Disease Index (PDI). Similarly, gingival concentration of IgE in these patients is also elevated with periodontal disease. ${ }^{14}$

\section{UPPER RESPIRATORY TRACT INFECTIONS}

Conditions affecting upper respiratory tract have been shown to be associated with simultaneous periodontitis and productive cough. Productive cough, nasal secretions, post nasal drip along with periodontitis near maxillary sinus can lead to a syndrome called dent bronchial syndrome which is three times more common than in general population in those having cough and periodontitis due to chronic smoking for several years. Patients with upper respiratory involvement present with productive cough, nasal drips, and sometimes associated fever. ${ }^{39}$ Oral cavity and upper respiratory track are the main ports of entry of microorganisms into the human body. ${ }^{50}$

\section{FACTORS RESPONSIBLE IN INVOLVING LUNGS SECONDARY TO PERIODONTITIS}

There are many conditions associated with poor oral hygiene such as dental caries, periodontitis, and gum infections and inflammatory conditions that changes the physiological flora and chemical composition in the oral cavity, causing reactions in tissues of oral cavity and other distant sites of body. ${ }^{51-54}$ Patients with COPD were much older than control group with significantly high level of serum matrix metalloproteinases and tissue inhibitors of matrix metalloproteinases, especially MMP-13, MMP-8, and TIMP-1 as determined by immunofluorometric studies (IFMA) and ELISA which suggest that these systemic inflammatory markers tend to increase in COPD, but clinically in this study, the relation between periodontitis and respiratory disease was not supported due to lack of association between clinical appearance of periodontitis and biochemical findings. ${ }^{55}$ Edentulism (total loss of teeth) increases risk of developing COPD like events and other respiratory illnesses, such as pneumonia and emphysema comparing to those having teeth and good periodontal hygiene. This risk was proven to be independent of sex, age, race, education, smoking, BMI, and hypertension. In addition to this, IL- 6 and $C$ - reactive protein (CRP) was also raised in these patients having symptoms of COPD. It was suggested that these events occur due to spill over of pulmonary system with organisms or irritants that accumulate in denture biofilms which caused periodontitis and simultaneously COPD like events a bit late in time. ${ }^{43}$ Periodontal infections may not directly cause systemic involvement of lungs but it is clear from the above discussion that these two processes are interlinked through various common risk factors such as potentially common pathogenic organisms involved in both the diseases. Therefore, it is clear that periodontal diseases are not only limited to periodontum but involves a wide range of systemic processes and thus, a dentist need to take care of bigger responsibilities to look for overall health care of the patients. Many of the recent studies show an association between poor oral health and respiratory diseases in which high risk subjects are a major concern especially immune-compromised. ${ }^{30}$

\section{CONCLUSIONS}

Periodontitis influence the course of pulmonary illnesses and can be a source of aspiration of oral secretions into the lungs. It is also major source of pulmonary infections. In addition to the saliva enzymes, certain cytokines, such as IL-6, originating from periodontal infected tissues enhance the pathogenesis of respiratory infections. Good oral health and hygiene can reduce the load of oropharyngeal colonization by harmful pulmonary pathogens, and therefore, may reduce the overall risk of respiratory infections.

\section{REFERENCES}

1. Dumitrescu AL. Etiology and pathogenesis of periodontal disease. Berlin: Springer-Verlag; 2010. p. 1-38.

2. Cullinan MP, Ford PJ, Seymour GJ. Periodontal disease and systemic health: current status. Aust Dent J. 2009; 54Suppl 1:s62-9. [PubMed]

3. Ansari Moghadam S, Abbasi S, Sanei Moghaddam E, Ansari- Moghaddam A. Is HbA1c an accurate predictor for diabetes risk in patients with chronic periodontitis? Iran J Public Health. 2014;43(8):1165. [PubMed]

4. Megson E, Kapellas K, Bartold PM. Relationship between periodontal disease and osteoporosis. Int J Evid Based Health. 2010;8:129-39. [PubMed]

5. Blaizot A, Vergnes JN, Nuwwareh S, Amar J, Sixou M. Periodontal diseases and cardiovascular events: metaanalysis of observational studies. Int Dent J. 2009;59: 
The Associations between Periodontitis and Respiratory Disease

197-209. [PubMed]

6. Xiong X, Buekens P, Vastardis S, Yu SM. Periodontal disease and pregnancy outcomes: state-of-the-science. Obstet Gynecol Surv. 2007;62:605-15. [PubMed]

7. Detert J, Pischon N, Burmester GR, Buttgereit F . The association between rheumatoid arthritis and periodontal disease. Arthritis Res Ther. 2010;12:218. [PubMed]

8. Azarpazhooh A, Leake JL. Systematic review of the association between respiratory diseases and oral health. J Periodontol. 2006;77:1465-82. [PubMed]

9. Scannapieco FA, Bush RB, Paju S. Associations between periodontal disease and risk for nosocomial bacterial pneumonia and chronic obstructive pulmonary disease. A systematic review. Ann Periodontol. 2003;8:54-69. [PubMed]

10. Hill K, Goldstein RS, Guyatt GH, Blouin M, Tan WC, Davis LL, et al. Prevalence and under diagnosis of chronic obstructive pulmonary disease among patients at risk in primary care. CMAJ. 2010;182:673-8. [PubMed]

11. Ingram RH, compiler. In: Chronic bronchitis, emphysema, and airways obstruction. In: Isselbacher KJ, Braunwald E, Wilson JD, et al. Harrison's principles of internal medicine. New York: McGraw Hill; 1994. p. 1197-206.

12. Gomes-Filho IS, Passos JS, Seixas da Cruz S. Respiratory disease and the role of oral bacteria. J Oral Microbiol . 2010 Dec;2. [PubMed]

13. Hayes C, Sparrow D, Cohen M, Vokonas PS, Garcia RI The association between alveolar bone loss and pulmonary function: the VA Dental Longitudinal Study. Ann Periodontol.1998;3:257-61. [PubMed]

14. Scannapieco FA, Papandonatos GD, Dunford RG. Associations between oral conditions and respiratory disease in a national sample survey population. Ann Periodontol.1998;3: 251-6. [PubMed]

15. Russell SL, Boylan RJ, Kaslick RS, Scannapieco FA, Katz RV. Respiratory pathogen colonization of the dental plaque of institutionalized elders. Spec Care Dentist .1999;19:128-34. [PubMed]

16. Scannapieco FA. Role of oral bacteria in respiratory infection. Journal of Periodontology. 1999;70:793-802. [PubMed]

17. Garcia RI, Nunn ME, Vokonas PS . Epidemiologic associations between periodontal disease and chronic obstructive pulmonary disease. Ann Periodontol. 2001;6:71-7. [PubMed]

18. Hyman JJ, Reid BC. Cigarette smoking, periodontal disease and chronic obstructive pulmonary disease. J Periodontol. 2004;75:9-15. [PubMed]

19. Kowalski M, Kowalska E, Split M, Split W, WierzbickaFerszt A, Pawlicki L, et al. Assessment of periodontal state in patients with chronic obstructive pulmonary disease Part II. Pol Merkur Lekarski. 2005;19:537-41. [PubMed]

20. Leuckfeld I, Obregon-Whittle MV, Lund MB, Geiran O, Bjørtuft $\varnothing$, Olsen I. Severe chronic obstructive pulmonary disease: association with marginal bone loss in periodontitis. Respir Med. 2008;102:488-94. [PubMed]

21. Deo V, Bhongade ML, Ansari S, Chavan RS. Periodontitis as a potential risk factor for chronic obstructive pulmonary disease: a retrospective study. Indian J Dent Res. 2009;20:466-70. [PubMed]

22. Fatemi K, Banihashemrad S, Tovhidi M, Hosseini S . Evaluation of the relationship between periodontal disease and chronic obstructive pulmonary disease. J Mash Dent Sch. 2009;33:214-6.

23. Wang Z, Zhou X, Zhang J, Zhang L, Song Y, Hu FB, et al. Periodontal health, oral health behaviours, and chronic obstructive pulmonary disease. J Clin Periodontol. 2009;36:750-5. [PubMed]

24. Prasanna SJ . Causal relationship between periodontitis and chronic obstructive pulmonary disease. J Indian Soc Periodontol. 2011;15:359-65. [PubMed]

25. Si Y, Fan H, Song Y, Zhou X, Zhang J, Wang Z. Association between periodontitis and chronic obstructive pulmonary disease in a Chinese population. J Periodontol. 2012;83(10):1288-96. [PubMed]

26. Zhou X, Han J, Song Y, Zhang J, Wang Z. Serum levels of 25-hydroxyvitamin D, oral health and chronic obstructive pulmonary disease. J Clin Periodontol. 2012;39: 350-6. [PubMed]

27. Katancik JA, Kritchevsky S, Weyant RJ, Corby P, Bretz W, Crapo RO, et al. Periodontitis and airway obstruction. J Periodontol. 2005;76:2161-7. [PubMed]

28. Terpenning MS, Taylor GW, Lopatin DE, Kerr CK, Dominguez BL, Loesche WJ. Aspiration pneumonia: dental and oral risk factors in an older veteran population. J Am Geriatr Soc. 2001;49:557-63. [PubMed]

29. Terpenning MS. The relationship between infections and chronic respiratory diseases: an overview. Ann Periodontol. 2001;6:66-70. [PubMed]

30. Sharma N, Shamsuddin H. Association between respiratory disease in hospitalized patients and periodontal disease: a cross-sectional study. JPeriodontol. 2011;82:1155-60. [PubMed] 
31. Mojon P. Oral health and respiratory infection. J Can Dent Assoc. 2002;68:340-5. [PubMed]

32. Liu Z, Zhang W, Zhang J, Zhou X, Zhang L, Song Y, et al. Oral hygiene, periodontal health and chronic obstructive pulmonary disease exacerbations. J Clin Periodontol. 2012;39:45-52. [PubMed]

33. Scannapieco FA, Ho AW. Potential associations between chronic respiratory disease and periodontal disease: analysis of National Health and Nutrition Examination Survey III. J Periodontol. 2001;72:50-6. [PubMed]

34. Zeng X-T, Tu M-L, Liu D-Y, Zheng D, Zhang J, Leng W. Periodontal disease and risk of chronic obstructive pulmonary disease: a meta-analysis of observational studies. PLoS ONE. 2012;7(10):e46508. [PubMed]

35. Page RC, Eke PI. Case definitions for use in populationbased surveillance of periodontitis. J Periodontol. 2007 Jul;78 Suppl 7:1387-99. [PubMed]

36. Bansal M, Khatri M, Taneja V. Potential role of periodontal infection in respiratory diseases - a review. J Med Life. 2013 Sep;6(3):244-8. [PubMed]

37. Cullinan MP, Seymour GJ. Periodontal disease and systemic illness: will the evidence ever be enough? Periodontol 2000. 2013;62(1):271-86. [PubMed]

38. Moghadam SA, Faghihi S, Amid R, Kadkhodazadeh M, Hosseini SK. Comprehensive oral rehabilitation of a patient with aplastic anemia by periodontal and prosthesis treatments. Compend Contin Educ Dent. 2012;33(4):e626. [PubMed]

39. Malathi K , Sujatha S. Periodontal disease and respiratory disorders. International Journal of Dental Research. 2013;1(2):30-4.

40. Mojon P, Bourbeau J. Respiratory infection: how important is oral health? Curr Opin Pulm Med. 2003;9:166-70. [PubMed]

41. Wilson M, Reddi K. Cytokine-inducing components of periodontopathogenic bacteria. J Periodontal Res. 1996;31:393-407. [PubMed].

42. Barros SP, Suruki R, Loewy ZG, Beck JD, Offenbacher S, Torres JP. A cohort study of the impact of tooth loss and periodontal disease on respiratory events among COPD subjects: modulatory role of systemic biomarkers of inflammation. PLoS ONE. 2013;8(8):e68592. [PubMed]

43. Levison ME. Pneumonia, including necrotizing pulmonary infections (lung abscess). In: Isselbacher KJ, Braunwald E, Wilson JD, et al., Harrison's principles of internal medicine. New York: McGraw Hill; 1994. p. 1197-206.
44. Scannapieco FA, Mylotte JM. Relationships between periodontal disease and bacterial pneumonia. J Periodontol. 1996;67:1114-22. [ㅁubMed]

45. Dietrich T, Sharma P, Walter C, Weston P, Beck J. The epidemiological evidence behind the association between periodontitis and incident atherosclerotic cardiovascular disease. J Periodontol. 2013;84 (Suppl 4):S70-84. [PubMed]

46. Linden G J, Lyons A, Scannapieco FA. Periodontal systemic associations: review of the evidence. J Clin Periodontol. 2013;40 (Suppl 14):S8-19. [PubMed]

47. HuangYJ, Lynch SV.The emerging relationship between the airway microbiota and chronic respiratory disease: clinical implications. Expert Rev Respir Med. 2011;5(6):809-21. [PubMed]

48. Eberhard J, Melk A, Kerling A, Stiesch M, Tegtbur U, Haverich A, et al. Moderate and severe periodontitis are independent risk factors associated with low cardiorespiratory fitness in sedentary non-smoking men aged between 45 and 65 years. J Clin Periodontol. 2014;41(1):31-7. [PubMed]

49. Macovei L, McCafferty J, Chen T, Teles F, Hasturk H, Paster BJ, et al . The hidden 'mycobacteriome' of the human healthy oral cavity and upper respiratory tract. J Oral Microbiol. 2015 Feb; 7:26094. [PubMed]

50. Usher AK, Stockley RA. The link between chronic periodontitis and COPD: a common role for the neutrophil? BMC Med. 2013;11(1):241. [PubMed]

51. Shirzaiy M, Ansari SM, Dehghan JH, Ghaeni SH. Total antioxidant capacity of saliva in chronic periodontitis patients before and after periodontal treatment. J Nepal Health Res Counc. 2014 Sep-Oct;12(28):172-6. [PubMed]

52. Shirzaiy M, Sarani Z, Bagheri S. Miswak/Derum manipulation, a common habit in Baluchestan, Iran. Int J High Risk Behav Addict. 2016;5(2):e25948. [PubMed]

53. Shirzaiy M ,Heidari F, Dalirsani Z, Dehghan J. Estimation of Salivary Sodium, Potassium, Calcium, Phosphorus and Urea in Type II Diabetic Patients. Diabetes Metab Syndr. 2013;9(4),332-6. [PubMed]

54. Yildirim E, Kormi I, Başoğlu K, Gürgün A, Kaval B, Sorsa T, et al. Periodontal health and serum, saliva matrix metalloproteinases in patients with mild chronic obstructive pulmonary disease. J Periodontol Res. 2013;48(3):269-75. [PubMed] 